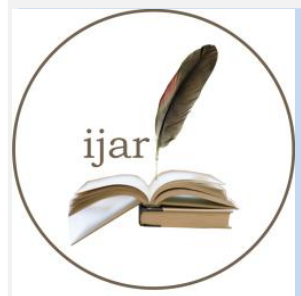

ISSN NO. $2320-5407$
Journal Homepage: -www.journalijar.com INTERNATIONAL JOURNAL OF ADVANCED RESEARCH (IJAR)

Article DOI:10.21474/IJAR01/1539

DOI URL: http://dx.doi.org/10.21474/IJAR01/1539

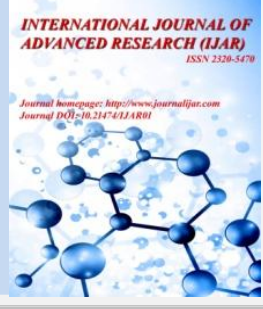

RESEARCH ARTICLE

\title{
STUDY ON THE GROWTH PERFORMANCE OF AEROBIC RICE INTERCROPPING WITH VIGNA RADIATAAND ARACHIS PINTOI.
}

Shampazuraini. S, Husein. AG, SitiAminah. W and NurHasanah. S.

Faculty of Plantation and Agrotechnology, UiTM Melaka (Jasin Campus), 77300 Merlimau, Melaka Malaysia.

\section{Manuscript Info}

Manuscript History

Received: 12 July 2016

Final Accepted: 19 August 2016

Published: September 2016

Key words:-

Aerobic rice, leguminous cover crop, growth performances, biomass

\section{Abstract}

Leguminous cover crops (LCCs) are vital for sustainable crop production and soil fertility. Besides, cover crops are grown for the purpose of covering the soil to protect it from the force of erosion. They can also disturb weed growth, disease infection and insect cycles. The objective of this research were (1) to examine the competition between weed with aerobic rice in term of the growth performance of aerobic rice, and (2) to identify the most potential of legume cover crop (Vigna radiata or Arachis pintoi) to the growth of aerobic rice. The experiment was conducted at the share farm of UiTM Jasin from September until November 2015. The treatments consist of aerobic rice without LCC (T0), aerobic rice with Vigna radiata (T1) and aerobic rice with Arachis pintoi (T2). The treatments were arranged in a Complete Randomized Design (CRD) with five replications. The parameter measured in this study are height of aerobic rice plant, number of leave of aerobic rice plant, number of tiller of aerobic rice plant and biomass production and partitioning measurement for stem, leave, panicle and root. The collected data was analyzed by using SPSS system (version 22). From the study, descriptive graph shows that, there were different trend for all three treatment. Biomass production of all treatments, shows a significant difference. From the study, Arachis pintoi shows the best result on the growth of aerobic rice. Aerobic rice intercropping with Arachis pintoi was recorded the highest difference than others treatment for biomass production and partitioning measurement.

Copy Right, IJAR, 2016,. All rights reserved.

\section{Introduction:-}

In Asia, nearly $90 \%$ of the world's rice is produced and consumed thus making rice become the most important food crop in Asia. Moreover, rice has become staple food for nearly 2.4 billion people in Asia, and except for some part of China and India and Pakistan, rice produce two thirds of the calories for most Asians according to rice-based diets (Food and Agricultural Organization, 2004). Rice production in Malaysia still dominates as the smallholder in the market. Thailand and Vietnam have to import between 600,000 and 700,000 tons of rice (FAMA, 2010). In Malaysia, there are eight rice granary areas which include Kerian-Sungai Manik Integrated Agriculture Development Area; Muda Agriculture Development Authority (MADA); Seberang Perak Integrated Agriculture Development Area; Kemubu Agricultural Development Authority (KADA); Penang Integrated Agricultural Development Area; Barat Laut Selangor Integrated Agriculture Development Area; North Terengganu Integrated 
Agriculture Development (KETARA) and Integrated Agriculture Development KemasinSemarak with total 677 acres / 884 hectare (DOA, 2010).

To improve the performance growth aerobic rice, it required sufficient of nutrient in the soil. The organic matter is one of the best techniques to improve chemical and physical of soil where it can increase the water holding capacity, improve the soil aggregates and soil structure. Organic matter can be in many forms such as dung, compost or green manure of Legume Cover Crop (LCC). Legume is different widely in their ability to prevent erosion, suppress weeds and add organic matter to the soil (Clark and Andy, 2007).

Vigna radiata and Arachis pintoi are the known to be used in the aerobic rice field. Vigna radiata is a fast-growing and warm-season legume. It does not required large amounts of water $(600-1000 \mathrm{~mm}$ rainfall / year) and it is drought tolerant. The mung bean grows on a wide range of soils but prefers well-drained loams or sandy loams, with $\mathrm{pH}$ ranging 5 to 8 (Mogotsi, 2006). Arachis pintoi is tolerant of flooding and will survive in area with annual rainfall of $1000 \mathrm{~mm}$ or less. It can tolerate any soil condition with $\mathrm{pH}$ ranging from about 4.5 - 7.2.

The main problem is managing the weeds in the aerobic rice field. Thus, weeds cause competition in term of space, nutrient, water and sunlight. These may affect aerobic rice growth performance, stunted and reduce of yield production. Aerobic rice would have to be harder than its predecessors so it could dominate the weeds (Junelyn, 2012). By planting the legume cover crop, it will decreases amount of unwanted weed from taking up nutrient for the plant and at the same time improving the soil fertility. These legumes are importance as it is the beneficial weeds that contribute in suppressing the weed and help solving this main problem in aerobic rice field.

Therefore, this study was focusing to examine the competition between weed with aerobic rice in term of growth performance of aerobic rice also to identify the most potential legume cover crops (Vigna radiata or Arachis pintoi) intercropped with the growth of aerobic rice.

\section{Material and Method:- \\ Study area:-}

The experiment was carried out at University Technology Mara, Jasin, Malacca, for three months period based on varieties estimation period of time. This study involved in field experiment and laboratory analysis. Field experiment was carried out at UiTM Jasin open area while laboratory analysis was conducted in Chemistry laboratory

\section{Planting material and medium:-}

This experiment using Aerobic rice (MRIA collected from MARDI, Vigna radiata seeds and Arachis pintoi cutting as planting material. Aerobic seeds and Vigna radiata seeds were planted directly on the bed at the open area of UiTM Jasin. Organic soil was used during planting of the Arachis pintoi cutting in the tray as the soil medium.

\section{Aerobic rice intercropping with Vigna radiate:-}

The leguminous Vigna radiatawas planted together during aerobic paddy planting. Vigna radiatawas planted at the plot for Treatment (T1) only. 6 plants of Vigna radiatawere planted for each treatment and each replication. Therefore, the plots that consist of Vigna radiataare Treatment 1 Replication 1 (T1R1), Treatment 1 Replication 2 (T1R2), Treatment 1 Replication 3 (T1R3), Treatment 1 Replication 4 (T1R4) and Treatment 1 Replication 5 (T1R5).

\section{Aerobic rice intercropping with Arachis pintoi:-}

Arachis pintoiwas planted by cutting technique where the stem with bud was choosing to germinate in the tray. Germination tray was placed in the greenhouse andwas watering the plant twice per day. 14 days of germination with emergence of some leafs, the seedling were transplanted to the open area intercropping with aerobic rice early in the morning to minimize the plant shock due to the environment changes. Arachis pintoiwas planted at the plot for Treatment 2 only. Six plants of Arachis pintoiwere planted for each treatment and each replication. Therefore, the plots that consist of Arachis pintoiare Treatment 2 Replication 1 (T2R1), Treatment 2 Replication 2 (T2R2), Treatment 2 Replication 3 (T2R3), Treatment 2 Replication 4 (T2R4) and Treatment 2 Replication 5 (T2R5).

\section{Experimental design:-}

The experimental design that will be used for this experiment is Complete Randomized Design (CRD). The seedling was placed randomly with 3 treatments and 5 replications. 


\section{Data collection:-}

Parameters measured in this study are plant height, number of leaf, number of tiller and biomass production and partitioning measurement

Plant height measurement was collected at second week, fourth week, sixth week, eight week and tenth week after planting until the 70th days. The measurement was taken from ground level to the tip of the highest shoot by using a measuring tape $(\mathrm{cm})$. The height of paddy plant which was treated with two treatments of legume cover crop and five replications of each treatment was measured.

Number of leaves was counted manually every two weeks until weeks 10 from all the treatment.

Total number of paddy tillers was recorded at second week after planting until tenth week after transplanting. The number of tillers from each bed was counted manually.

The leaves, stem, panicle and root biomass was taken at the 70th days after sowing. The fresh part of rice leaves, stems, panicle and roots was dried out using oven (Oven Dryer (Memmert) Model UFE 500) and left for 48 hours at $70{ }^{\circ} \mathrm{C}$. After 48 hour, both portions were weight with electrical Top Loading Analytical Balance (T0309227) to determine the dry weight and data was recorded in gram $(\mathrm{g})$ unit.

\section{Result:-}

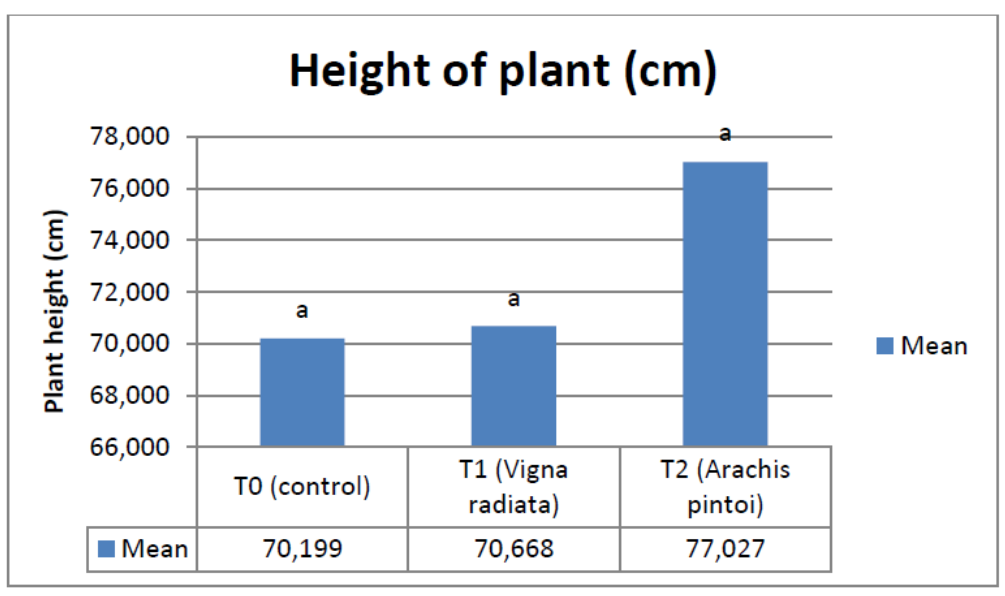

Figure 4.1: Average height of aerobic rice plant per treatment

Graph above shows the growth in the height of aerobic rice plant intercropping with two different LCC starting from the second weeks until the tenth weeks of the experiment. From the graph, it shows that the heights of each aerobic rice plant were steadily increasing throughout the experiment period. The graph also shows that aerobic rice plant under treatment T2 (aerobic rice with Arachis pintoi) has the highest plant height compare to other treatments. T1 (aerobic rice with Vigna radiata) was the second highest between the other treatments followed by T0 (aerobic rice). From the analysis using Tukey's family error rates, there is no significant different between all the treatments based on height of aerobic rice plant. 


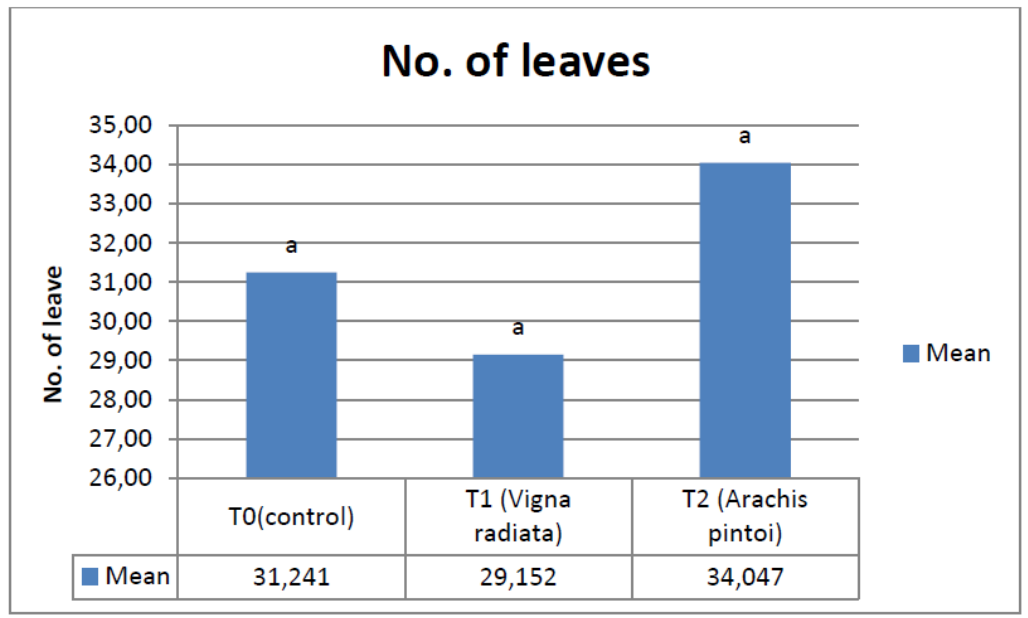

Figure 4.2: Average number of leaves per treatment

Graph above shows the mean of the number of leaves of aerobic rice plant per treatment. From the graph, T2 which is intercropping with Arachis pintoi shows the highest mean value followed by T0 (aerobic rice), while T0 (aerobic rice with Vigna radiata) shows the lowest mean value of number of leaves. From the analysis using Tukey's family error rates, there is no significant different between all the treatments based on number of leaves of aerobic rice plant.

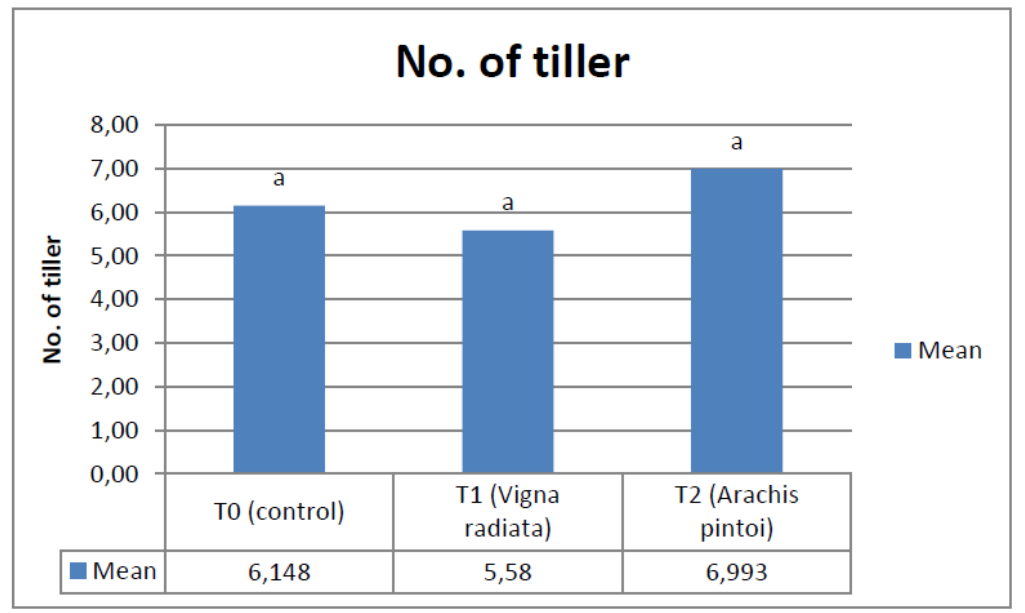

Figure 4.3: Average number of tiller per treatment

Graph above shows the mean number of tiller of aerobic rice plant per treatment. From the graph, T2 which is intercropping with Arachis pintoishows the highest mean value followed by T0 (aerobic rice), while T1 (aerobic rice with Vigna radiata) shows the lowest mean value of number tiller. From the analysis using Tukey's family error rates, there is no significant different between all the treatments based on number of tiller of aerobic rice plant. 


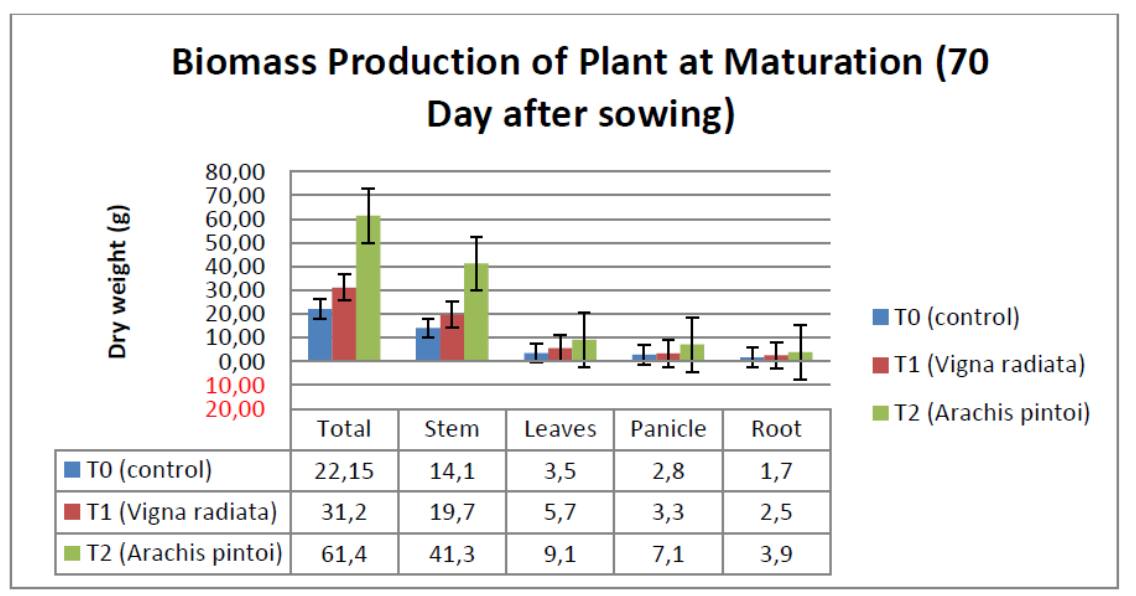

Figure $A$ A Rismace nroduction and nartitioning ner treatment

Graph above shows the biomass production of aerobic rice plant of the treatment at maturation stage (DAS 70). Based on the graph, it indicates that the dry weight of each parts of plant and also the total dry weight of the plant. Biomass production for T2 (aerobic rice intercropping with Arachis pintoi) is higher compare to T1 (aerobic rice with Vigna radiata) and T0 (aerobic rice). It is shows that, the difference of total biomass production in T2 is twofold more compare to T1 and T0. Stem contribute the highest dry weight of plant parts in both treatments and then followed by leave dry weight. On the other hand, it is shows that panicle dry weight is higher than root dry weight in all treatment.

The paired samples test table indicates that, there is significant different of total biomass production between T0 (aerobic rice), TI (aerobic rice with Vigna radiata) and T2 (aerobic rice intercropping with Arachis pintoi). It shows that the p value is 0.016 less than 0.05 with95\% confidence interval. Based on the part of plant, the panicle, stem, leave and root dry weight is significant between the treatments with p value in paired samples test are $0.022,0.019$, 0.010 and 0.008 respectively.

\section{Discussion:-}

Growth performance of plant:-

Plant height and number of tiller is part of the criteria in paddy performance. This is also indicating that the higher the plant and the more tiller produce by the plant, it shows that the paddy is in a healthy condition.

From the data, the plant height and number of tiller shows no significant different between all treatments. The $p$ value in SPSS shows is higher than 0.05, where the $\mathrm{p}$ value for plant height is 0.886 and number of tiller is 0.819 . Whereas for the number of leave, it shows a non-significant different between all treatment where the $\mathrm{p}$ value is 0.944. From the descriptive data, the highest measurement for height of aerobic rice plant is treatment T2 (aerobic rice with Arachis pintoi) because Arachis pintoi has a high nutritive value and low fiber content (Firth et al. 2002; Neef 2004) and it has fast nutrient cycling than most plants (De Oliveira et al. 2003).

Factors that lead to the non-significant different is the environmental factor such as during raining season, the rain drop has high velocity and give impact to the soil for erosion to happen. Thus, it may lead to nutrient leaching where the plants do not get enough of nutrient for optimum growth. On the other hand, the surrounding planting area has variety of crop planted around the planting plot for aerobic rice and it also attracts pest and disease to attack the aerobic rice at leave and stem area.

\section{Biomass production measurement:-}

It was found that, there was significant different of total biomass production between treatment control, treatment T1 (aerobic rice with Vigna radiata) and treatment T2 (aerobic rice with Arachis pintoi). The p value for leave dry weight is 0.010 , root dry weight is 0.008 , stem dry weight is 0.019 and panicle dry weight is 0.022 . From the Tukey method, treatment T2 (aerobic rice with Arachis pintoi) is the best treatment and a good recommendation to suggest to the farmers to apply this treatment due to the significant different show in this result. The previous study that was done by M.B Sakato and Muhammad (2014) states that the dry matter accumulation, translocation process and 
photosynthesis process is contribute to the biomass production of aerobic rice. In addition, the root biomass of the Arachis pintoi improves the porosity, structure and density of the soil.

\section{Conclusion:-}

By referring to the result of the study, it can be concluded that all the three treatment which have no significant influence on the growth performance of aerobic plant. On the other hand, biomass production is the only parameter that shows significant influence on the growth performance of aerobic plant.

\section{Acknowledgement:-}

Alhamdulillah, thanks to Allah S.W.T for giving us HIS blessing, health, patience, and motivations in completing report. The authors are thankful to the Management of Faculty of Plantation and Agrotechnology, UniversitiTeknologi MARA for their constant support and encouragement. Also to everyone that helping in completing this experiment directly or indirectly is highly appreciated.

\section{References:-}

1. Clark, Andy (ed.). (2007). Managing cover crops profitably, 3rd ed. Sustainable Agriculture Network, Beltsville, MD.

2. De Oliveira CA, Muzzi MRS, Purcino HA, Marriel IE and De Sa MH. 2003. Decomposition of Arachis pintoi and Hyparrheniarufa litters in monoculture and intercropped systems under lowland soil. Pesq. Agropec. Bras. Brasilia 8(9) 1089-1095.

3. Firth Dj, Jones RM, MCFayden LM, Cook BG and Whalley RDB. 2002. Selection of pasture species for groundcover suited to shade in mature macadamia orchards in subtropical Australia. Tropical Grasslands 36:112

4. FAO. (2008). Conservation Agriculture. Food and Agriculture Organization of the United Nations, Rme, Italy. Retrieved on April 27th, 2014, from http:/www.fao.org/ag/ca.

5. Junelyn S.D.R. (2012). Aerobic rice: Growing rice with less water. Bureau of Agricultural Research. Vol 4 No 4.

6. Mogotsi, K. K. (2006). Vigna radiata(L.) R. Wilczek. In: Brink, M. \& Belay, G. (Editors). PROTA 1: Cereals and pulses/Céréalesetlégumes secs. [CD-Rom]. PROTA, Wageningen, Netherlands.

7. Neef A. 2004. Integrating participatory elements into conventional research projects: Counting the costs and measuring the benefits http:/?www.prgaprogram.org/IAWFTPpapers/Neef-2.pdf.14p. (Accessed in 10/26/2007). 